\title{
Constancy and Change in the Prevalence and Frequency of Offending When Based on Longitudinal Self-reports or Official Records: Comparisons by Gender, Race, and Crime Type
}

\author{
Rolf Loeber $^{1}$ - David P. Farrington ${ }^{2}$. \\ Alison E. Hipwell ${ }^{1} \cdot$ Stephanie D. Stepp ${ }^{1}$. \\ Dustin Pardini ${ }^{1} \cdot$ Lia Ahonen $^{3,1}$
}

Received: 17 December 2014 / Revised: 29 March 2015 / Accepted: 10 April 2015 /

Published online: 3 May 2015

(C) Springer International Publishing AG 2015

\begin{abstract}
Introduction The study examines age-crime prevalence and age-crime frequency curves based on longitudinal data from boys in the Pittsburgh Youth Study and girls in the Pittsburgh Girls Study.

Results Results show that the prevalence of the age-crime curve for theft and violence (based on self-reports or police charges) followed the typical age-crime curve for males and slightly less distinctly for females, with the peak of offending occurring earlier for self-reports than for police charges. The decrease in police charges for violence and theft took place at an earlier age for females than males, but this was not distinct when self-reported delinquency was the criterion. The mean frequency of self-reported theft and violence followed the age-crime curve for males but not for females, who showed a mean frequency of offending which was more constant. In contrast, the mean frequency of police charges increased with age for males and females. Comparing AfricanAmerican and Caucasian males and females shows a higher prevalence but not a higher mean frequency of self-reported offending.

Conclusions The results are reviewed in the light of other studies, and the policy implications of the findings are discussed.
\end{abstract}

Keywords Age crime curve P Prevalence · Frequency · Delinquency · Violence · Theft Police charges $\cdot$ Self-reports $\cdot$ Race

Rolf Loeber

loeberr@upmc.edu

1 University of Pittsburgh, Pittsburgh, PA, USA

2 University of Cambridge, Cambridge, England

3 Örebro University, Örebro, Sweden 
The age-crime curve is well known, showing that during late childhood and adolescence, there is a major increase in the number of youth who engage in delinquent acts and that this number starts to decrease in late adolescence and into young adulthood $[12,23]$. This rise and fall tends to be perpetual from one age cohort to the next over time. Scholars have occasionally studied these changes, but it is remarkable that several key issues remain unsolved (well-articulated by [31], p. 59). Examples of these issues are whether the mean frequency of offenses by active offenders changes during this time window, the extent to which the age-crime frequency curve mirrors the rise and fall of the age-crime prevalence curve, and whether such mirroring occurs for both selfreported delinquency and official charges. Other examples are the differences in the developmental timing and acceleration of violent compared with property offenses, the timing and extent of gender differences unfolding with age, and the extent to which the development of offending by different racial groups diverges with age. Importantly, many studies on age-crime curves have not distinguished between within- and between-individual changes in offending over time, with the former being the best type of data derived from longitudinal compared with cross-sectional studies.

The common aggregate of the age-crime curve is most often based on a combination of prevalence and frequency, and these need to be studied separately [28]. Thus, in this paper, we will make a clear distinction between age-crime prevalence curves and agecrime frequency curves. The former represent changes with age in the proportion of offenders in a population, whereas the latter, sometimes referred to as lambda [3], represents changes with age in the mean frequency of offending for active offenders (omitting those who do not offend at a given age). In terms of measurement, both agecrime prevalence and age-crime frequency curves can be based on self-reported delinquency or on official records of offending (i.e., arrest, charges, or convictions). Longitudinal data on the age-crime curve, whether in terms of prevalence or mean frequency, have not been widely published (but see $[12,25]$ ). Further, most of the knowledge on the age-crime curve is based on data from males and few studies have reported on females $[12,10]$. This dearth of information is particularly problematic because some authors have indicated that the age-crime prevalence curve for females peaks earlier than that for males $[12,9]$, while other authors have reported the opposite $[32,39]$.

There are several reasons why the population age-crime prevalence and the agecrime frequency curves are important for the study of life-course offending $[20,31]$ :

a) In longitudinal data sets, the shape of the age-crime prevalence curves represents the proportion of individuals who commit one or more delinquent acts, and at what ages that proportion peaks and then declines.

b) Knowledge of the age-crime frequency curves represents the total number of crimes committed by active offenders at different ages, and for that reason, when based on longitudinal data, represents the total delinquent activity by an age cohort of offenders.

c) Knowledge of the age-crime frequency and prevalence curves is a key to explain why prevalence and/or frequency changes, peaks, or remains constant with age.

We will now briefly review the present state of knowledge on age-crime prevalence and age-crime frequency curves, the difference between curves based on self-reports vs. 
official records, curves comparing African-American and Caucasian youth, and curves comparing theft vs. violence. However, when comparing age-crime prevalence curves and age-crime frequency curves, it should be kept in mind that they are based on different metrics: prevalence and mean frequency scales, with each usually having different distributions and different meanings in terms of increases or decreases. For example, an increase in the prevalence from 20 to $40 \%$ of individuals cannot be equated to an increase in the mean frequency of offending from 20 to 40 delinquent acts per year.

Age-Crime Prevalence Curves The study of the development of offending during adolescence and early adulthood as expressed in the age-crime prevalence curve is now well established [12, 20, 23]. For example, the age-crime prevalence curve was thought to be universal [20] at least for males but is higher for certain populations of youth. For example, the peak of the prevalence curve is higher when adjusted for co-offending ([31], Fig. 8.1; [33, 37]), the curves are higher for males than for females, for youth in disadvantaged compared with advantaged neighborhoods [9, 11], and for youth with parent-reported adjustment and antisocial problems [9]. Further, longitudinal analyses show that the height of the age-crime prevalence curve is predicted by the individual's level of cognitive impulsivity and intelligence [26].

The caveats, however, are that most published studies on the age-crime prevalence curves are based on official records of arrest or conviction rather than self-reports, and most of the studies represent cross-sectional data and therefore confound age and secular changes in offending. For that reason, longitudinal data based on the followup of the same subjects over time, thus allowing the study of within-subject changes in offending over time, which is particularly valuable because secular effects can then be ruled out.

Age-Crime Frequency Curves Compared with age-crime prevalence curves, have been much less studied [2, 20, 10]. From a developmental psychology perspective, it is likely that the mean frequency of delinquent acts from late childhood through early adulthood follows the same shape as the age-crime prevalence curve. This is suggested by the waxing and waning of impulsive behaviors, sensation seeking [26], planning ahead, time perspective, and anticipation of future consequences during that developmental period [34]. Further, it can be argued that when individuals desist from offending, this is preceded by a decrease in the mean frequency of delinquent acts.

Several authors have maintained, however, that, in contrast to the age-crime prevalence curve, there is no consistent relationship between age and the mean frequency of offending by active offenders [4-6, 12, 31, 32]. In contrast, Michael Gottfredson and Travis Hirschi $[18,15,16]$ have posited that an individual's offending rate declines as the adult offender ages, but their arguments apply more to offenders in general populations rather than to active offenders. All of the preceding authors, however, based their empirical work or their opinions on official records rather than self-reports of offending.

In a test of these opposing arguments, Loeber and Snyder [27] found that the mean number of official offense episodes (the term referred to in that paper) between the ages 9 and 16 followed an s-shaped curve, accelerating between ages 9 and 13, and subsequently decelerating. In contrast, Elonheimo et al. [10], who also used official records, found that the mean frequency of offending among active offenders based on police reports showed little change over time for violent offenses, whereas property 
crimes followed the typical age-crime curve. It remains to be seen whether these divergent results hold when other indicators of official offending are used such as the mean frequency of police charges per year. Also, research on mean frequencies has largely focused on male offenders, and it is unclear whether age-crime frequency curves for females mirror those for males, or whether they are less consistent or constant.

\section{Curves Based on Self-Reports Compared with Curves Based on Official}

Records There is increasing research showing that for each official record of offending among active offenders, there are on average five or more self-reported offenses by female and male offenders $[1,13,14,36]$. The research also shows that the scaling up factor varies by age during adolescence. Thus, research needs to clarify to what extent, age-crime prevalence and age-crime frequency curves based on official records, such as the mean frequency of police charges, mirror the mean frequency of self-reported offending during adolescence.

Curves Comparing Offending by African-American and Caucasian Youth It is well-known that, on average, African-American males have a higher prevalence of offending than Caucasian males, and that race differences for females are in the same direction [9]. Also, research shows that the age-crime curves for African-American males and females spans a wider developmental period indicative of longer criminal careers (e.g., [7, 40]). However, it is less clear whether the peaking of offending in African-American youth occurs earlier than for Caucasian youth. Further, some researchers found a double peak of offending for African-American but not for Caucasian men, with the second peak occurring in the late twenties [9]. As to the mean frequency of offending, Piquero et al. [30] indicate that it is about the same for individuals of different races. However, it is not clear whether this applies to both self-reports and official reports of offending.

Questions to be addressed in this paper:

1. How do age-prevalence curves and age-frequency curves compare for males and females, and how do the curves compare when based on self-reports or on police charges?

2. Are there differences in the age-crime curves when violence is contrasted with theft?

3. How do the curves differ for African-American females and males compared with Caucasian females and males? And is the magnitude of gender difference in offending the same for African-American and Caucasian males and females?

The data to be used to address the above questions come from two community-based longitudinal studies, the Pittsburgh Girls Study and the Pittsburgh Youth Study.

\section{Methods}

The Pittsburgh Girls Study (PGS) is a longitudinal study which started in 2000 with yearly follow ups of females in the city of Pittsburgh. Some of the unique features of the PGS are: a large community sample of 2451 females and multiple informants 
(the females, their parents, and teachers). The initial participation rate over the four cohorts was $85 \%$ of all identified families that were eligible for participation (see [17]). The study has a high average retention rate of over $90 \%$ across 14 annual assessment, and retention in any year never dropped below $85 \%$. The focus of the assessments is on the development of delinquency, mental health problems, substance use, and prosocial behavior from childhood (ages 5 to 8 years) extending into late adolescence/early adulthood (ages 19 to 22 years). The study examines a large range of risk and protective factors that impact the course of delinquent development in females.

The sample consists of four cohorts (initial ages 5, 6, 7, 8), approximately 600 in each cohort [17]. Since the prevalence of female delinquency is much lower compared with that of males, oversampling was performed of the most disadvantaged neighborhoods $(100 \%$ in disadvantaged neighborhoods, $50 \%$ in advantaged neighborhoods, according to US Census data). Valid data on delinquency police charges ranged between 91 and $93 \%$, due to missing cases that moved out of the county or were deceased. For this study, we used self-report data from all four cohorts between ages 11 and 18. Further, we used official records from age 10 until age 21 to investigate whether the females had been charged by the police with any type of serious offenses (see measurement section for inclusion criteria).

Across the four cohorts, $52.9 \%$ were of African-American race, $41.2 \%$ of the females were Caucasian white, and $5.9 \%$ were reported as other race of origin (latter two groups are called Caucasian). The large majority (93\%) of the females were living with their biological mother. Most of the females attended public schools (82.6\%), $16.5 \%$ attended private schools and only a fraction $(0.9 \%)$ was homeschooled. Because there were no major cohort differences in terms of demographics such as SES, living conditions, and family constellations, all four cohorts were included in the present study. By 2014, seven individuals had died and those individuals have been eliminated from analyses. There are no indications that the PGS has systematically lost participants from certain groups. More details of how the PGS team ensured high participation rates, and the details of data can be found in Keenan et al. [19].

The Pittsburgh Youth Study (PYS) is a longitudinal study which began in 1987 when the males participating in the study were in grades 1 (youngest cohort), 4 (middle cohort), and 7 (oldest cohort) in public schools in Pittsburgh (for details of the study, [24]). All public schools with one exception participated in the study. The initial cooperation rates were high $(84.6,86.3$, and $83.9 \%$ families agreed to participate, for the oldest, middle, and youngest sample, respectively).

To identify and capture as many high risk males as possible, an initial screening was performed based on multiple informants (boy, parent, teacher) to create an overall risk score (detailed in [24]). The males in the top $30 \%$ of the high risk score were identified as more antisocial than others and were included in the follow-up analyses, along with a roughly equal number of males randomly selected from the remaining $70 \%$ of the distribution. In this particular study, we use data from the youngest sample $(N=503)$ for which the longest follow-up information is available from a young age. The youngest cohort has been assessed 18 consecutive times between ages 7 and 19, and two additional times at ages 25 and 28. The average retention rate for the youngest sample is $92.1 \%$ [24]. The main reasons for excluding the middle cohort with its first assessment at age 10 are the absence of regular assessments after age 13 (due to financial restraints), while the oldest cohort was excluded because its assessments started at age 13 [22]. 
The racial composition of males in the youngest cohort was $58 \%$ African-American, $41 \%$ Caucasian, and $1 \%$ other race (latter two groups are called Caucasian). The large majority $(95 \%)$ of the males were living with their biological mother. No significant systematic differences have been found in racial distribution or school achievement tests between the screening and follow-up samples [21]. The latest data collection of official records of offending was in 2012, when the participants in the youngest cohort were about age 32. By 2014, 16 men in this sample had died and those individuals have been eliminated from analyses.

There are no indications that the PYS has systematically lost participants from certain groups. More details of how the PYS team ensured high participation rates, and the details of data can be found in Stouthamer-Loeber and Stallings [35].

Measurements and Age Groups The age windows for the assessment of the males and females differed. Females were assessed via self-reported delinquency from age 11 through 18, and males were assessed with the same measure from ages 9 to 25 . Gender comparisons based on self-reported delinquency can thus be made from ages 11 through 18, while gender comparison based on official records (delinquency charges) can be made from ages 10 to 21. Data on self-reported delinquency and delinquency charges beyond age 18 are presented for males in the PYS to gauge the course of offending and the age-crime curve at later ages.

Self-Reported Delinquency Self-reported delinquency was measured through the Self-reported Delinquency Questionnaire (SRD) both in the PGS and the PYS on a yearly basis. The 40 items of the SRD are based on the National Youth Survey and has been widely evaluated (e.g., [8, 35, 25]). For each item, the individual was asked if he or she had committed it, and if so, how many times. Examples of items were: How many times did you carry a concealed weapon during the last twelve months? How many times did you destroy others' property during the last 12 months? The response alternatives ranged from zero to $\mathrm{n}$ (no upper limit). The following items were included in moderate and serious violence: gang fight, robbery, assault, and attack with weapon. Moderate and serious theft offenses were stealing $>\$ 5$, pickpocketing, stealing from car, dealing with stolen goods, breaking and entering, joyriding, and auto theft. The same items were used for males and females, and these items were added to create the total delinquency score.

Criminal Records Juvenile records were acquired from Allegheny County Juvenile Probation Office (JPO) for the PGS participants. For the PYS participants, juvenile records were obtained from the Allegheny County Juvenile Court (prior to 2001) for males in the PYS, and the Pennsylvania Juvenile Court Judges' Commission (only in 1997). For the PGS, the JPO office provided data on participants aged 18 and older according to name, current address(es), date of birth, and/or Social Security number (SSN). The data included information about police charges. For the PYS, the Allegheny County Juvenile Court records were searched and coded for offense date, offense category, and disposition according to the format developed by Weinrott [38] and further improved by Maguin [29]. 
Adult Criminal Records Every PGS participant was searched via the Court of Common Pleas web docket system for ages 18-21 for Pennsylvania only. Dockets were identified two ways: first three letters of first name and first three letters of last name + date of birth (DOB); full first and last name, blank DOB. If records were found using either method they were considered a match. All found dockets were printed and double-entered into a database. Information about arrests, charges, dispositions, fines, and incarcerations/probations was entered. Any double-entry discrepancies were investigated and corrected.

Information about adult criminal records [35] for the PYS participants was provided by the Pennsylvania State Police Repository, Court of Common Pleas web docket and the Federal Bureau of Investigation (FBI). The latest data collection was performed in 2012. The coding system followed the definitions of crimes in the FBI Uniform Crime reports and corresponds with the National Center for Juvenile Justice.

\section{Presentation of Data and Analyses}

Data were summarized to explore and describe the characteristics of possible differences in age-crime prevalence and age-crime frequency curves. Bivariate analyses were executed to compare the possible differences between prevalence of delinquency in males and females respectively, and also by race. More specifically we compared Caucasian (C) males, Caucasian females, African-American (AA) males, and African-American females.

Weighting of Prevalence Data Both the PYS and the PGS at the first assessment used a screening procedure to increase the number of at risk youth at the beginning of each study (a screening tool for the PYS and an overrepresentation of the most disadvantaged neighborhoods for the PGS). To obtain population values for the prevalence of self-reported delinquency and the prevalence of police charges, a weighting procedure was applied that corrected for the screening. However, this could not be done for mean frequency of offending or the mean frequency of police charges because the number active offenders varied for each age.

Age Trends The peak age of violent and theft offenses were investigated for males and females, together with the shape of the different curves in term of average, median, 25th and 75th percentiles, and skewness. In general, an age-crime curve is said to only have one peak (unimodal), but in reality, this is more complicated when measuring different types of crime and different populations [12]. This is partly why this study relies on explorative descriptive statistics, including skewness as an index of nonlinear changes in curves over time and kurtosis to establish the degree to which scores remain constant with age. Further, in the present paper we defined a constant prevalence curve as one which stays within a three percent range, whereas a constant age-crime frequency curve was defined as one which maximally varied within a mean range of three offenses per year. 


\section{Results}

\section{Age-Crime Prevalence Curves}

Gender Differences Not surprisingly, Table 1 shows that the overall prevalence of self-reported total offenses was higher for males than females of each race. The agecrime curves for the prevalence of self-reported delinquency are shown in Fig. 1a. For each gender the prevalence of self-reported delinquency follows the age-crime curve with both males and females peaking in offending during mid-adolescence (about ages 13 to 15). Remarkably, gender differences in the prevalence of self-reported violence with age were small, compared with the gender difference in the prevalence of theft, which was larger (Fig. 1b). When discussing race differences, we will return to this finding of the closely related developmental curves for violence for each gender. In contrast, the gender results for self-reported theft are very different with the age pattern showing a distinct age-crime curve for males, and a much lower and flatter curve for females, which is confirmed by the high kurtosis values shown in Table 1.

Turning to police charges, does the age-crime prevalence curve also apply to the prevalence of police charges for violence and theft in males and females, respectively? Figure 1c shows that there is indeed an age-crime curve for each, which is most distinct for males, and again lower and flatter for females. Judging from police charges, females also appear to grow out of theft and violence at a much younger age (about age 18 decreasing to $0.3 \%$ ) than males (see Fig. 1c, d), but the self-reported delinquency data on the other hand show that 5.3 and $2.6 \%$ of the females and males were still engaged in violence and theft at age 18, respectively (Fig. 1a, b).

Race It is well known that more African-American males and females self-report offending than Caucasian males and females (e.g., [5]). Table 1 shows the descriptive statistics for self-reported offenses between ages 11 and 18. The prevalence of AfricanAmerican offenders was substantially higher than for Caucasian offenders, but the difference was much more marked for females (a factor of more than two: 43.9 vs. $18.8 \%$ ) than males (a factor of 1.3: 54.8 vs. $42.3 \%$ ). The magnitude of gender differences in the prevalence of self-reported offenders within each ethnic group were much smaller for African-Americans (females $43.9 \%$ vs. males: $54.8 \%$ ) but were much larger for Caucasians (18.8 vs. $42.3 \%$ ).

How do the age-crime prevalence curves compare for African-American females and males compared with Caucasian females and males? Figure $2 \mathrm{a}, \mathrm{b}$ show that the age-crime prevalence curve of self-reported offenders (theft and violence) was higher for African-American compared with Caucasian males and females. In all comparisons, the age-crime prevalence curve of offenders followed the age-crime curve, with the caveat that the curve for Caucasian females was flattest compared with the curves of African-American females and males of each race. At the peak of the age-crime curve (ages 14-15), the prevalence of African-American male offenders was a third higher than that of Caucasian males, and the prevalence of African-American female offenders was more than twice that of Caucasian females.

Table 2 summarizes the descriptive statistics for ages 10-21 for police charges. More than twice as many African-American than Caucasian males were charged (61.4 vs. $27.7 \%$ ) and this was even higher (by a factor of almost seven) for females 


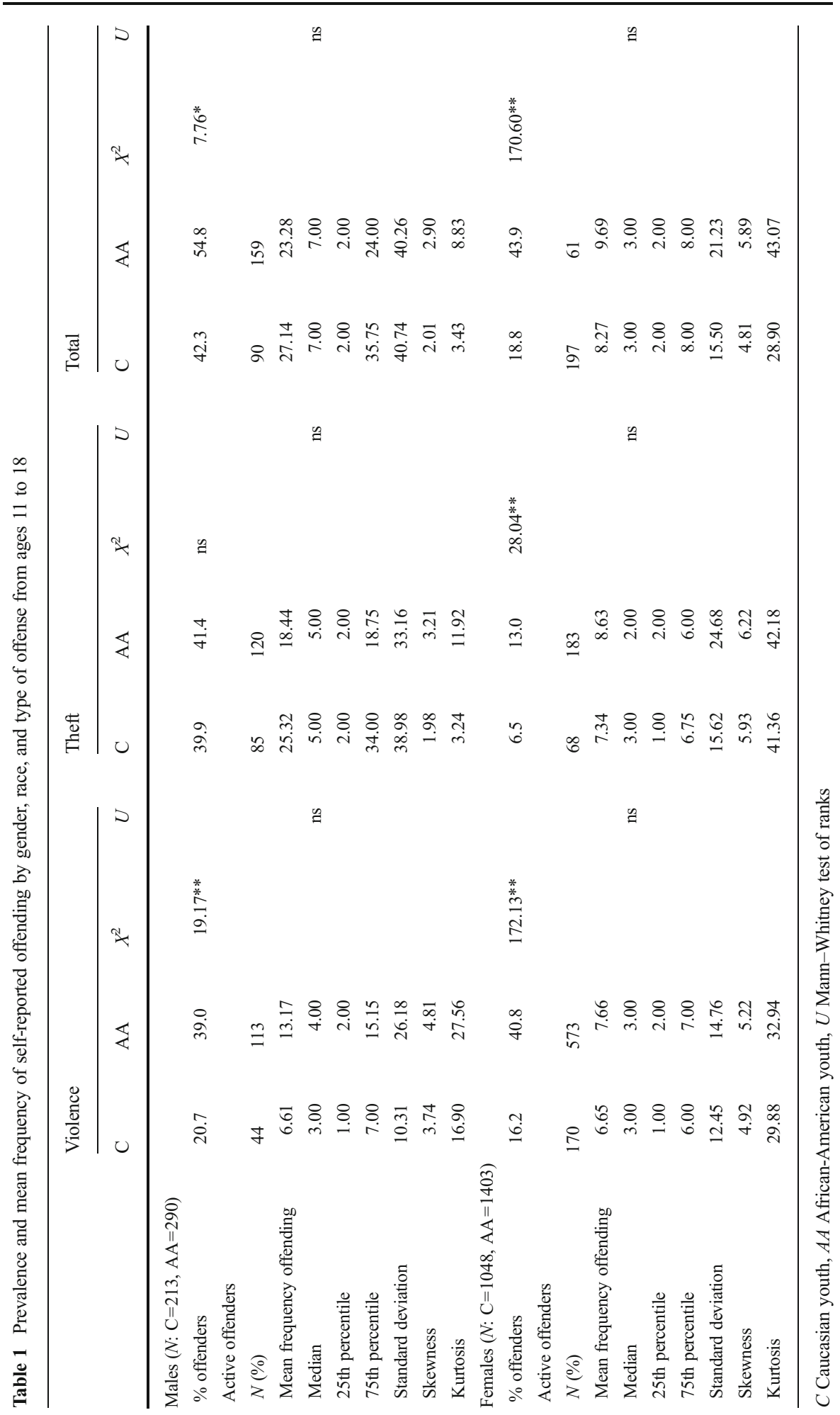



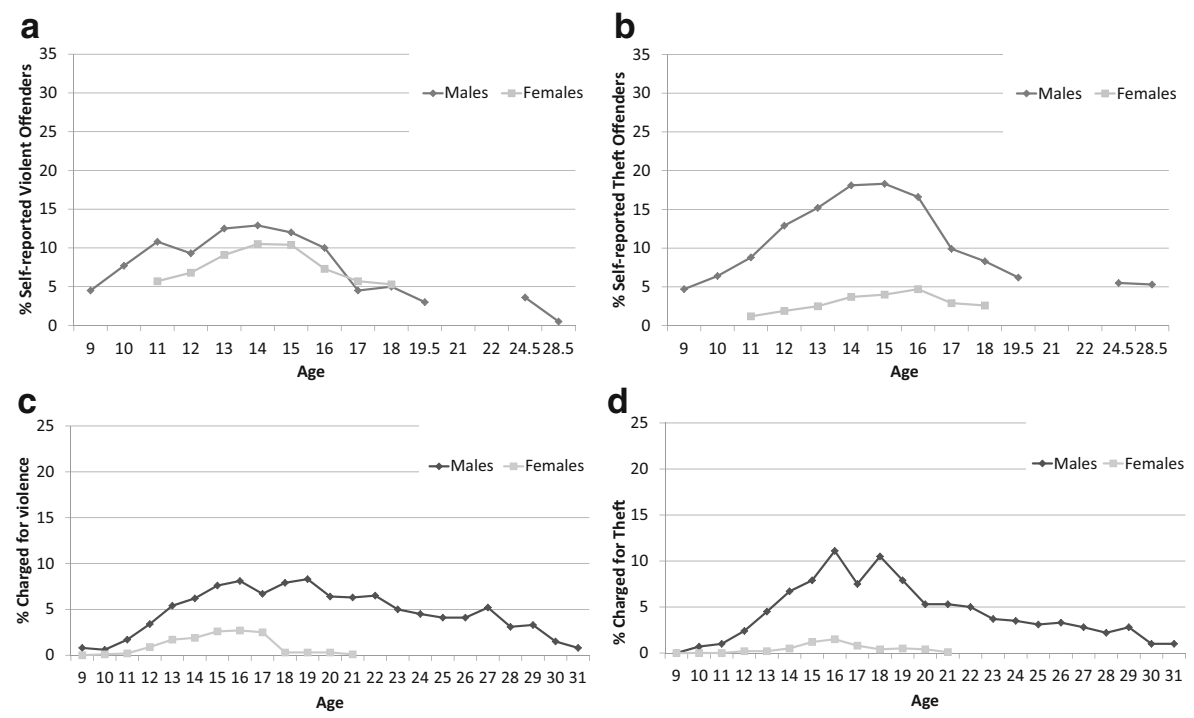

Fig. 1 a Prevalence of self-reported violent offenders by gender. b Prevalence of self-reported theft offenders by gender. c Prevalence of police charges for violence by gender. d Prevalence of police charges for theft by gender

(20.4 vs. $2.9 \%$ ). Thus, racial differences in delinquency were substantially higher for charges than for self-reported prevalence of offending (Table 1). The age-crime curves for the prevalence of individuals charged by the police mirror race in three out of the four instances followed the shape of age-crime curves (Fig. 2c, d); the exception was the prevalence of police charges of Caucasian females where the curve was basically flat (Fig. 2d). The magnitude of race differences was large: at the peak age of 15, twice as many of the African American compared with Caucasian males were charged by the police, while for females at the peak of age 16 there were six times as many AfricanAmerican than Caucasian females who were charged by the police.

\section{Age-Crime Frequency Curves}

We now turn to the mean frequency of offending for each gender and the two racial groups.

Gender Figure 3a shows that for active offenders, the mean frequency of males' selfreported violence increased with age until age 16 and then started to drop, but for females, such a developmental peak was not apparent, and instead the results showed a much flatter curve. A somewhat similar pattern was again visible when the outcome was self-reported theft for each gender (Fig. 3b), peaking at 15 and 17 for males, but was basically constant for females.

How do these results compare with the mean frequency of police charges for active offenders? Figure $3 c$ shows that for males, the mean frequency of police charges for violence gradually increased between ages 10 and 16 and then, although somewhat fluctuating, remained rather constant until the last available data at age 31 . For females, 

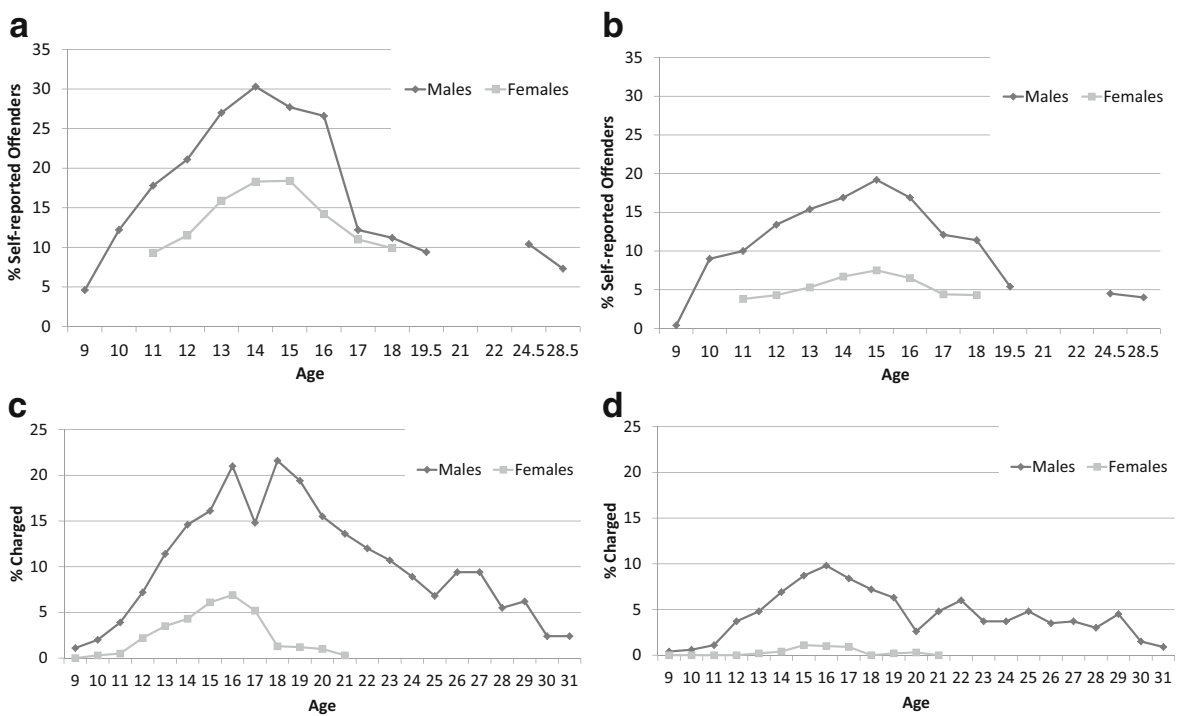

Fig. 2 a Prevalence of self-reported African-American offenders by gender (theft and violence combined). b Prevalence of self-reported Caucasian offenders by gender (theft and violence combined). c Prevalence of police charges for delinquency by African-American males and females (theft and violence combined). d Prevalence of police charges for delinquency by Caucasian males and females (theft and violence combined)

however, the mean rate of violent charges was rather constant between late childhood and up until age 16, peaking at ages 18 to 19, decreasing after that.

Are these results mirrored for theft? Figure $3 \mathrm{~d}$ shows that for males, the mean frequency of self-reported theft increased from late childhood until about age 12 after which it remained mostly constant, although dropping at age 26 and ages 30-31. For charged female offenders, the mean frequency of police charges for theft increased from ages 11 to 18 and then stabilized until the last measurement at age 21, and did not drop as was the case for mean frequency of police charges for violence (in contrast, the median value was the same-1-for theft and violence). A decrease in the mean frequency of police charges for theft might occur after age 21, but currently, we do not have complete data beyond that age. In summary, the mean frequency of theft charges increased for male and female active offenders. Recall that the age-crime prevalence curves based on self-reports were flatter for females than those for males. Does this apply to age-crime frequency curves of police charges as well? The kurtosis index in Table 2 indicates that this was not consistently the case.

Race Table 1 shows that the mean frequency of self-reported offending by active African-American offenders was not very different compared with that of active Caucasian offenders (for males, 23.28 vs. 27.14; for females, 9.69 vs. 8.27), while the median values were identical for the racial groups, but they differed by gender (seven for males and three for females). Table 1 also gives an overall indication of the variability of the mean frequency of offenses with age. The standard deviation (theft and violence combined) was similar for African-American and Caucasian male offenders but was much higher for African-American than Caucasian female offenders, indicating much higher variability among African-American female offenders. Moreover, 


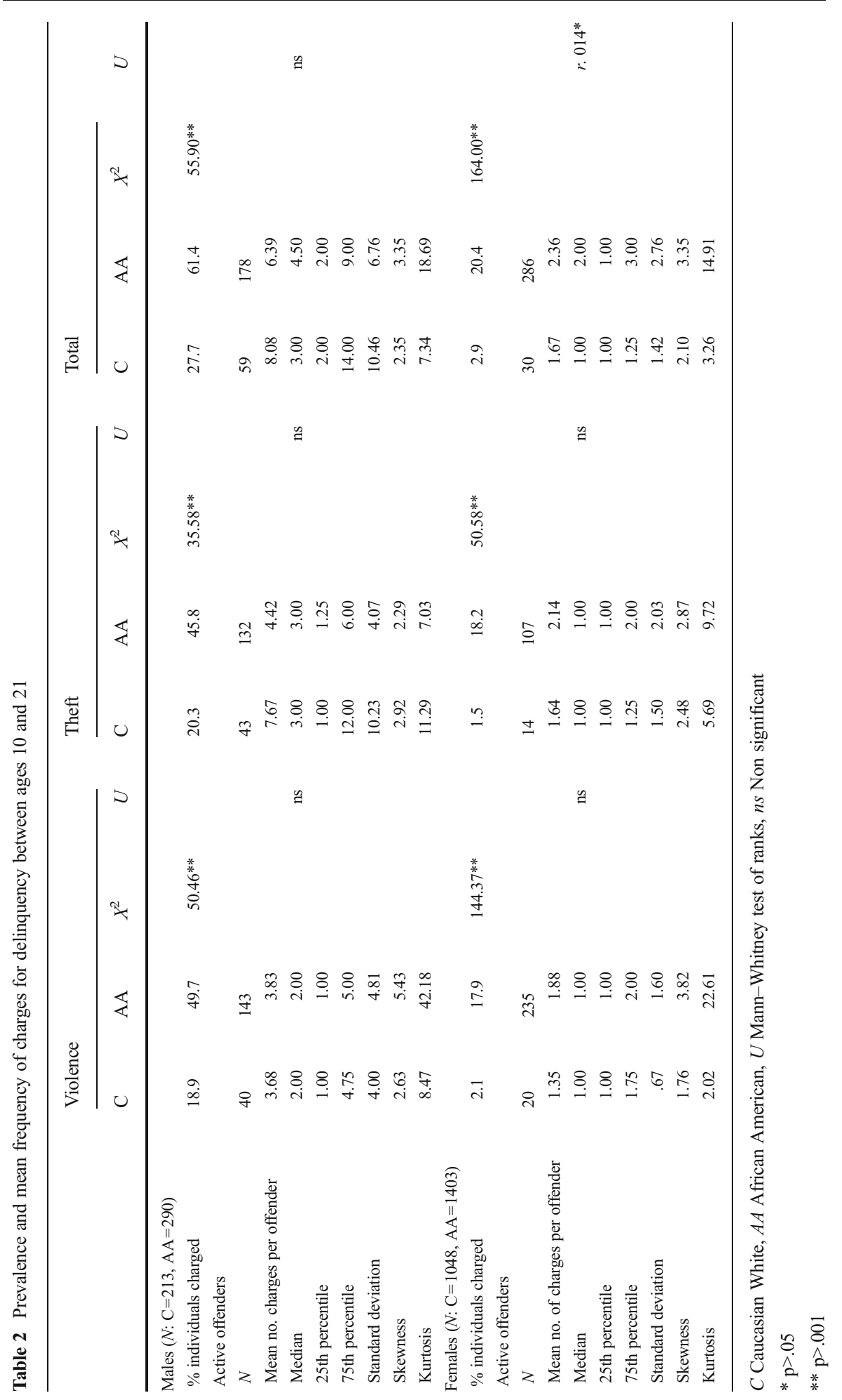



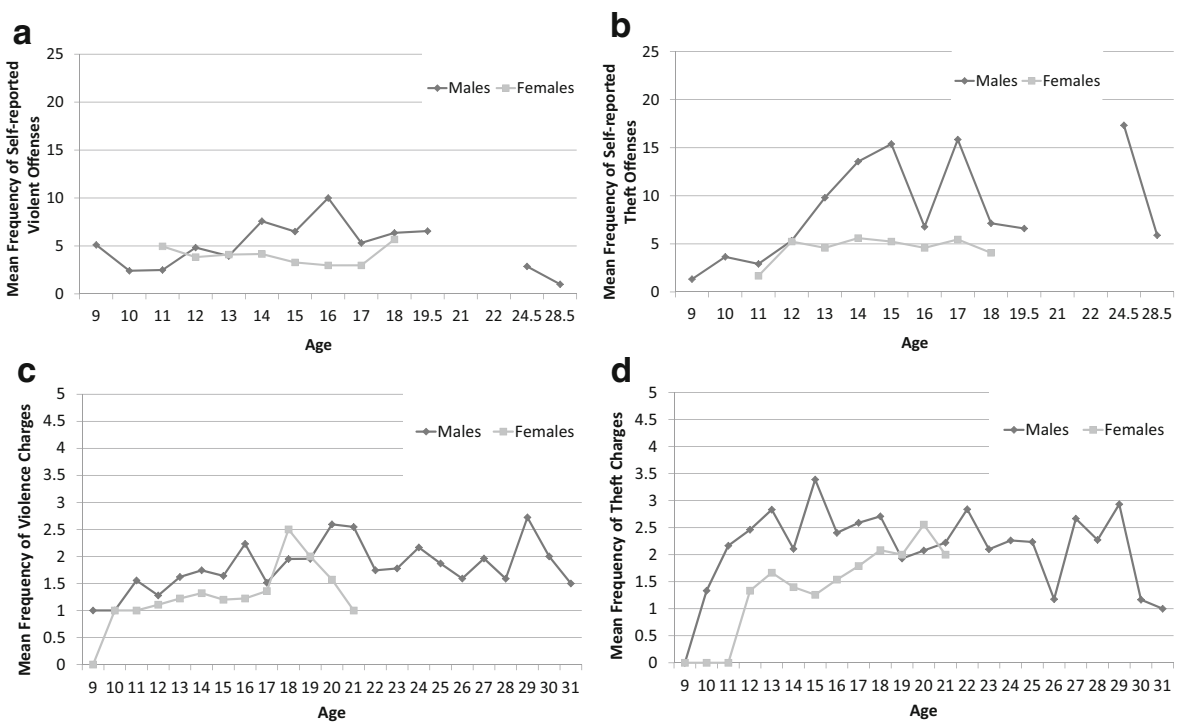

Fig. 3 a Mean frequency of self-reported violent offenses by male and female active offenders. b Mean frequency of self-reported theft offenses by male and female active offenders. c Mean frequency of police charges for violence by male and female active offenders. $\mathbf{d}$ Mean frequency of police charges for theft by male and female active offenders

Table 1 shows that, with one exception, females of each race displayed a more constant mean frequency of self-reported offending.

Figure 4 a compares the frequency age-crime curves for self-reported delinquency in the two racial groups. The results show that the mean frequency of self-reported offending followed the age-crime curve for African-American males but not for African-American females, which aside from a slight upturn at age 18, was mostly constant. Figure $4 \mathrm{~b}$ show the equivalent for Caucasian youth. It shows wildly fluctuating mean frequency of offending ranging from an average of 3.0 at age 11 to 19.1 at age 17 to drop afterwards. In aggregate, the mean frequency of self-reported offending from ages 11-18 was similar for Caucasian and African-American males (27.14 vs. 23.28) and females ( 8.27 vs. 9.69); these results were supported by the median values which were both 7 for Caucasian and African-American males and both 3 for Caucasian and African-American females.

Turning to the mean frequency of police charges, Table 2 shows that this index was slightly higher for Caucasian compared with African-American male active offenders ( 8.08 vs. 6.35), but the reverse was the case for female active offenders (Caucasian vs. African-American: 1.67 vs. 2.36; however, note that the prevalence of active female Caucasian offenders who committed theft was very low). We also looked at the median which is less affected by the high variability of the distribution of offending. In most comparisons, the median of police charges was higher for African-American compared with Caucasian males and females (males 4.5 vs. 3; females 2 vs. 1), although the effect size for females was small $(r=.019)$.

What do age-crime curves look like when based on the mean frequency of police charges for each gender between the ages 10 and 21 ? Figure $4 \mathrm{c}$ shows the results for African-American males and females. The results indicate a gradual increase in the 

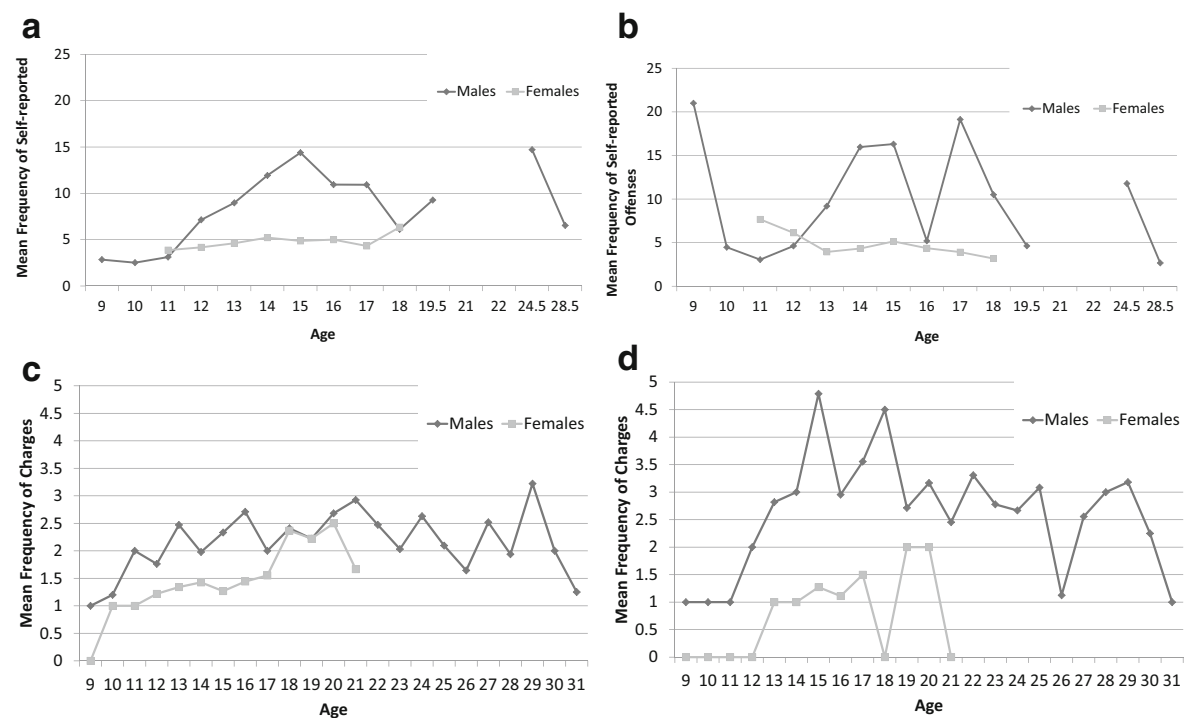

Fig. 4 a Mean frequency of self-reported offenses by African-American male and female active offenders (violence and theft combined). b Mean frequency of self-reported offenses by Caucasian male and female active offenders (violence and theft combined). c Mean frequency of police charges for delinquent acts by African-American male and female active offenders. d Mean frequency of police charges for delinquent acts committed by Caucasian male and female active offenders

mean frequency of police charges between ages 9 to 13 for each gender after which the mean frequency of police charges minimally increased and rather stayed constant. For African-American females, the mean frequency of police charges increased between ages 11 and 18 after which it started to drop. Although the mean frequency of police charges for African-American female active offenders tended to be lower than that for African-American males, this was very similar between ages 18 and 20 .

Are these results comparable for Caucasian youth? Figure $4 \mathrm{~d}$ shows that the mean frequency of police charges for Caucasian males increased after age 11, peaked at ages 14 and 18, and with some fluctuations stayed relatively constant between ages 13 and 27 , to drop after age 29. For Caucasian females, the mean frequency increased at age 13, and reached a peak at ages 20-21. Comparing African-American and Caucasian males, show higher variability for the former (see Table 2) and slightly higher median for African-American compared with Caucasian males and females (4.5 vs. 3.0; 2.0 vs. 1.0).

\section{Discussion and Conclusions}

The results shed light on consistencies and inconsistencies in age-crime prevalence and frequency curves for males and females of two race groups, covering theft and violence as evident from self-reported offending and police charges. It is probably fair to say that the prevalence and mean frequency of self-reported offending is a better indicator of actual delinquent behavior than is being charged by the police or the frequency of police charges. The main reasons are that police charges depend on surveillance 
practices, selected reports to the police by victims of crime, and the fact that the police correctly identifies only a proportion of offenders (e.g., [1, 13, 14, 36]). This implies that our question whether the age-crime curve is observable for the prevalence and mean frequency of offending by males and females can be best addressed when selfreports of offending are the criterion.

Self-Reported Delinquency for Males and Females The results for self-reported delinquency show that the age-crime prevalence curve for the shared time-window studied (ages 10 to 18) is more visible for males' violence and theft than for females' violence and theft (i.e., slightly weaker for theft by females). The findings on males agree with most prior longitudinal studies based on self-reported delinquency $[9,12,32]$, while the findings for females differ from those reported by Elliott, who noted a much more distinct age-crime prevalence curve in the National Youth Survey [9].

Turning to the mean frequency of self-reported delinquency, we found that the typical and traditionally shaped age-crime curve applied well to the males in this study, both for violence and theft. The curves for females were less consistent and tended to have a flatter shape, which indicates a more constant mean rate of offending over time. Thus, for males both the prevalence and frequency curves for total self-reported offending (i.e., violence and theft) followed the age-crime curve, but for females, this was only the case for the prevalence of self-reported violence and theft. Girls' mean frequency of offending did not follow the age-crime cure, which was not surprising given that this index is substantially lower for females than males. Comparison with other studies proved difficult because of lack of publications on this topic.

The results showed that in those instances, where the age-crime curve was recognizable, the curves for prevalence and mean frequency of self-reported offending often overlapped. The results show that the peak of the mean frequency of self-reported offending was slightly later than the prevalence peak of offending, and this applied to both violence and theft across gender.

The comparison of the timing of the peaking of offending by gender proved equivocal. For self-reports, the curves for females were much flatter than for males, and the priority of peak offending across gender could not be established. However, the peak of self-reported prevalence of violence and theft was slightly later for females than males, but this was less clear for the mean frequency of offending in either category.

Police Charges for Males and Females How do these age-related offending patterns reflect in police charges? Findings based on the prevalence of police charges with violence or theft between ages 9 and 21 follow the expected age-crime curve for males, but hardly for females. These results are largely in agreement (for males and females) with the findings in the Finnish study by Elonheimo et al. [10]. And what about the mean frequency of police charges? The results for males showed an increase in the mean frequency of police charges between ages 9 to 14/16 for violence and theft after which the rate of police charges, with some fluctuations became constant rather than decreases. These results are congruent with those reported by Elonheimo et al. [10] for theft by males although at a later age, and not for violence, which was low in prevalence and remained constant with age. For females in the present study, the mean 
frequency of police charges was more constant when it concerns violence but increased for theft and then becomes more constant.

Theft vs. Violence We found that the age-crime prevalence curves for violence and theft largely overlapped but that theft peaked earlier than violence, which is confirmed by most other studies [12]. For males, the prevalence curve of theft was higher than the prevalence curve of violence. We are at a loss to explain that for females the prevalence curve of violence was higher than the prevalence curve of theft.

Police Charges Compared with Self-Reports How well do age-related changes in offending match when based on the two sources of information? For this comparison, we will focus on the age period 11 to 18 , which is the age-interval shared by the two forms of measurements.

The findings show that for males the age-crime curves apply to both the prevalence of self-reported violence and theft and police charges, but for females only for selfreports and not for charges. When comparing the age-crime frequency curves for selfreports and police charges, we found a different pattern in males: whereas self-reported prevalence followed the age-crime curve, in the case of the mean frequency of police charges, only the upswing or upslope of that curve was apparent and not the downslope. For females, the comparison between the two types of measurements agreed less consistently.

When considering the less consistent finding across self-reported delinquency and mean frequency of police charges, it should be kept in mind that each is based on active offenders, but because of reduced detection rates by the police the active offenders only partly overlap with active offenders as evident from self-reports.

African-American vs. Caucasian Males and Females When we compared offending by African-American youth with Caucasian youth, the results agree that prevalence and frequency curves were uniformly higher for the former compared with the latter and that this applies to each gender [9]. The findings on charges indicate a much longer agecrime curve for African-American than Caucasian males (see also [9]). The age-crime curve was more visible for prevalence in three out of the four comparisons than the mean frequency of self-reports of offending or the mean frequency of police charges with age. When considered by gender, the results were slightly stronger for males of each racial group compared with females of each group.

Strengths and Limitations One of the strengths of the present study is the availability of police charges in addition to self-reports of offending. The age-crime curve observed for prevalence of self-reported offending by males was also visible in the age-crime curves for police charges, but with the latter occurring slightly later than the former, which is not surprising since police work follows offending patterns rather than the reverse. The results, however, show major differences in both the prevalence and mean frequency of offending when based on self-reports compared with official records. This indicates that different types of delinquency measures may produce very different results when based on the prevalence or mean frequency of offending as apparent from self-reports or official records. 
The study results should be considered with several caveats. The age window for self-reported offending by females in this study was narrower than that for males, and it remains to be seen whether age-crime curves in females are consistently different than those for males when more data on later ages becomes available. The results did not take into account co-offending. Further, it is unclear to what extent replication will be successful for other indicators of official processing, such as conviction for delinquent acts. The present results focused on aggregate findings from males and females, and African-American and Caucasian youth, and this paper was not the right place to focus on individual differences in offending among these categories of offenders. Finally, the present paper did not address why the prevalence and mean frequency of offending varied with age. It is plausible but as yet unproven that age has a direct effect on offending, presumably because of brain maturation [22], but social factors have also been put forward to explain the downslope of the age-crime curve [12, 22]. It should be kept in mind that the results presented in this paper focus on summary indicators of offending in longitudinal samples, and do not account for individual differences in offending trajectories over time. Thus, individuals may represent different ages of onset, persistence, and desistance patterns that are now hidden in the summary data.

On the positive side, this is the first paper that examines age-crime prevalence and frequency curves based on self-reports and official records for males and females, for violence and theft, and for African-Americans and Caucasians. The results seriously qualify the universality of the concept of age-crime curves, and qualify several of the basic parameters in criminology.

Acknowledgments The authors are indebted to Alfred Blumstein and Magda Stouthamer-Loeber and an anonymous reviewer for their comments on an earlier draft of the paper. Rebecca Stalling effectively assembled the data for analyses, while Jennifer Wilson kindly checked the references. The research on which this paper is based was funded by grants from the National Institute of Mental Health (MH056630, MH 48890, MH 50778), the Office of Juvenile Justice and Delinquency Prevention (2013-JF-FX-0058), the National Institute on Drug Abuse (DA411018), Pew Charitable Trusts, Office of Juvenile Justice and Delinquency Prevention (96-MU-FX-0012), the Pennsylvania Department of Health (SAP 4100043365), and the Swedish Research Council.

\section{References}

1. Ahonen, L., Loeber, R., Farrington, D. P., Hipwell, A., \& Stepp, S. (2014) Dark figures of delinquency in girls: discrepancies between and self-reports and official records. Paper presented at the annual meeting of the American Society of Criminology, San Francisco, CA.

2. Blumstein, A. (2012). Research on criminal careers, part 1: contributions, opportunities, and needs. In R. Loeber \& B. Welsh (Eds.), The future of criminology. New York: Oxford University Press.

3. Blumstein, A., \& Cohen, J. (1979). Estimation of individual crime rates from arrest records. Journal of Criminal Law and Criminology, 70, 561-585.

4. Blumstein, A., \& Cohen, J. (1987). Characterizing criminal careers. Science, 237, 939-991.

5. Blumstein, A., Cohen, J., Roth, J. A., \& Visher, C. A. (1986). Criminal careers and career criminals. Washington, DC: National Academy Press.

6. Blumstein, A., Cohen, J., \& Farrington, D. P. (1988). Criminal career research: its value for criminology. Criminology, 26, 1-36.

7. Elliott, D. S. (1994). Serious violent offenders: onset, developmental course, and termination-the American Society of Criminology 1993 presidential address. Criminology, 32, 1-21. 
8. Elliott, D. S., Huizinga, D., \& Ageton, S. (1985). Explaining delinquency and drug use. Beverly Hills, CA: Sage.

9. Elliott, Delbert S., David Huizinga, and Fred C. Pampel (2005) Youth violence: Continuity and desistance: a supplemental report to youth violence: a report of the Surgeon General. Washington, DC: Substance Abuse and Mental Health Services Administration

10. Elonheimo, H., Gyllenberg, D., Huttunen, J., Ristkari, T., Sillanmäki, L., \& Sourander, A. (2014). Criminal offending among males and females between ages 15 and 30 in a population-based nationwide 1981 birth cohort: results from the FinnCrime study. Journal of Adolescence, 37, 1269-1279.

11. Fabio, A., Li-Chuan, T., Loeber, R., \& Cohen, J. (2011). Neighborhood socioeconomic disadvantage and the shape of the age-crime curve. American Journal of Public Health, 101, S325-S332.

12. Farrington, D. P. (1986). Age and crime. In T. Michael \& M. Norval (Eds.), Crime and justice: an annual review of research. Chicago: Chicago University Press.

13. Farrington, D. P., Jolliffe, D., Loeber, R., \& Lynn Homish, D. (2007). How many offenses are really committed per juvenile court offender? Victims and Offenders, 2, 227-249.

14. Farrington, D. P., Ttofi, M. M., Crago, R. V., \& Coid, J. W. (2014). Prevalence, frequency, onset, desistance and criminal career duration in self-reports compared with official records. Criminal Behavior and Mental Health, 24, 241-253.

15. Gottfredson, M., \& Travis, H. (1986). The true value of lambda would appear to be zero. An essay on career criminals, criminal careers, selective incapacitation, cohort studies, and related topics. Criminology, 24, 213-234.

16. Gottfredson, M., \& Hirschi, T. (1988). Science, public policy, and the criminal career paradigm. Criminology, 26, 37-56.

17. Hipwell, A. E., White, H. R., Loeber, R., Stouthamer-Loeber, M., Keenan, K., Chung, T., \& Sembower, M. (2005). Young girls' expectancies about the effects of alcohol, future intentions and patterns of use. Journal of Studies on Alcohol, 66, 630-639.

18. Hirschi, T., \& Gottfredson, M. (1983). Age and the explanation of crime. American Journal of Sociology, $89,552-584$.

19. Keenan, K., Hipwell, A., Chung, T., Stepp, S., Stouthamer-Loeber, M., Loeber, R., et al. (2010). The Pittsburgh girls study: overview and initial findings. Journal of Clinical Child and Adolescent Psychology, 39, 506-521.

20. Loeber, R. (2012). Does the study of the age-crime curve have a future. In L. Rolf \& W. Brandon (Eds.), The future of criminology. New York: Oxford University Press.

21. Loeber, R., \& Farrington, D. P. (2011). Young homicide offenders and victims: development, risk factors and prediction from childhood. New York, NY: Springer.

22. Loeber, R., \& Farrington, D. P. (2012). From juvenile delinquency to adult crime: criminal careers, justice policy and prevention. New York, NY: Oxford University Press.

23. Loeber, R., \& Farrington, D. P. (2013). The age-crime curve and its relevance for policy and interventions. In B. Gerben \& W. David (Eds.), Encyclopedia of criminology and criminal justice. New York: Springer.

24. Loeber, R., Farrington, D. P., Stouthamer-Loeber, M., \& Van Kammen, W. B. (1998). Antisocial behavior and mental health problems: explanatory factors in childhood and adolescence. Mahwah, NJ: Lawrence Erlbaum.

25. Loeber, R., Farrington, D. P., Stouthamer-Loeber, M., \& White, H. R. (2008). Violence and serious theft: development and prediction from childhood to adulthood. New York: Routledge.

26. Loeber, R., Menting, B., Lynam, D., Moffitt, T., Stouthamer-Loeber, M., Stallings, R., et al. (2012). Findings from the Pittsburgh youth study: cognitive impulsivity and intelligence as predictors of the agecrime curve. Journal of the American Academy of Child and Adolescent Psychiatry, 51, 1136-1149.

27. Loeber, R., \& Snyder, H. N. (1990). Rate of offending in juvenile careers: findings for constancy and change in lambda. Criminology, 28, 97-109.

28. MacLod, J. F., Grove, P. G., \& Farrington, D. P. (2012). Explaining criminal careers: implications for justice policy. Oxford: Oxford University Press.

29. Maguin, Eugene (1994). Manual for retrieving Juvenile Court data from the Allegheny County Juvenile Court files. Unpublished manuscript, Western Psychiatric Institute and Clinic, University of Pittsburgh.

30. Piquero, A., Farrington, D. P., \& Alfred, B. (2003). The criminal career paradigm. In T. Michael (Ed.), Crime and justice (Vol. 30). Chicago: Chicago University Press.

31. Piquero, A., Farrington, D. P., \& Blumstein, A. (2007). Key issues in criminal career research. Cambridge: Cambridge University Press.

32. Piquero, A. J., David, H., \& Lila, K. (2012). Criminal career patterns. In L. Rolf \& D. P. Farrington (Eds.), From juvenile delinquency to adult crime: criminal careers, justice police and prevention. Oxford: Oxford University Press. 
33. Reiss, A. J., \& Farrington, D. P. (1991). Advancing knowledge about co-offending: results from a prospective longitudinal survey of London males. Journal of Criminal Law and Criminology, 82, 360-395.

34. Steinberg, L., Cauffman, E., Woolard, J., Graham, S., \& Banich, M. (2009). Are adolescents less mature than adults? Minors' access to abortion, the juvenile death penalty, and the alleged APA "flip-flop.". American Psychologist, 64, 583-594.

35. Stouthamer-Loeber, M., \& Rebecca, S. (2008). Measurement instruments and constructs. In L. Rolf, D. P. Farrington, M. Stouthamer-Loeber, \& H. R. White (Eds.), Violence and serious theft: development and prediction from childhood to adulthood. New York: Routledge.

36. Theobald, D., Farrington, D. P., Loeber, R., Pardini, D. A., \& Piquero, A. R. (2014). Scaling up from convictions to self-reported offending. Criminal Behavior and Mental Health, 24, 265-276.

37. Van Mastrigt, S. B., \& Farrington, D. P. (2011). Prevalence and characteristics of co-offending recruiters. Justice Quarterly, 28, 325-359.

38. Weinrott, Mark (1975). Manual for retrieval of Juvenile Court data. Unpublished manuscript, Evaluation research group, Eugene, Oregon.

39. Wikström, P.-O. (1990). Age and crime in a Stockholm cohort. Journal of Quantitative Criminology, 6, 61-64.

40. Wolfgang, M. E., Thornberry, T. P., \& Figlio, R. M. (1987). From boy to man, from delinquency to crime. Chicago: University of Chicago Press. 